| Volume: 1 | Number: 2 | October 2016 | ISSN: 2503 - 4405|

CONVERTING E-BOOK INTO AUDIOBOOK TO ENHANCE ENGLISH RECEPTIVE

SKILL

\author{
J. Ari Wibowo \\ j.ariwibowo24@gmail.com
}

\begin{abstract}
Recently, technology is getting common and cheap for people. It can be reached easily around them, even in their grasp. The development of smartphone and various free applications bring great opportunity and easiness in live and learning process as well. Their integration can be a potential media to improve learners' English competence, especially their receptive skill. There are three free apps needed to change e-book into audiobook in the smartphone, consist of FBReader, FBReader TTS plugin and Ivona. A common writing in the e-book can be change into a voice which one can hear with or without read it. It is a new way to practice and improve listening and reading skill. Here, some potentials, advantages and also pedagogical implications of them are elaborated. It is expected that learners can improve their English skills while having fun.
\end{abstract}

Keyword: FBreader, FBReader TTS plugin, Ivona, smartphone, receptive skill

\title{
Background
}

The development of technology has highly influenced human life and profession. It affects social system and personal's attitude in case of technology using. Nowadays it is also used for job management as its efficiency and effectiveness. It decreases time consumption on doing the work in which the productivity and the outcome automatically increase. In case of education, it is also useful to enhance students' skill especially English. Here, it talks about free android apps to develop students' receptive skill at once. There are three applications needed, they are FBReader, FBReader TTS plugin and Ivona amy English. As a foreign language, it can be trained by having repeated self practice. Those applications collaboration provide many times of reading and listening skill practice and many sources of e-book based on reader's taste to practice with. 


\section{Receptive Skill}

Receptive skill consists of listening and reading but not passive. It is a decoding skill on understanding, different from speaking and writing as an encoding skill. Listening is an essential skill, present in most of the activities we carry out throughout the lives, as Lindsay and Knight (2006: 45) said: we listen to a wide variety of things, for example; what someone says during a conversation, face to face or on the telephone; announcements giving information, for example, at an airport or railway station; the weather forecast on the radio; a play on the radio; music; someone else's conversation (eavesdropping); a lecture; professional advice, for example, at the doctor, in the bank; instruction, for example, on how to use a photocopier or other machinery; direction; a taped dialogue in class.

Every single child is born to have receptive sense, since then the child begins to receive various impression by them. A baby learns the mother tongue by listening skill instead of reading. It is obvious that listening skill is one of the information gate. It is very important skill which is frequently forgotten since many people think that it is a passive activity in the instruction. It should be well trained since listening skill is motor to enhance the learning process output. "Listening ability lies at the very heart of all growth, from birth through the years of formal education the better those learning skills are developed, the more productive our learning efforts"(Brown as cited in Vennum, 2015).

Another receptive skill is reading, a multi-faceted skill to derive meaning of the printed text accurately and efficiently. It is known that reading is a receptive skill in the form of written which need higher level ability consists of some series of lesser skills. However, reading effectively improves the level of proficiency. It can be done by self training activity. One can choose and train the reading skill based on his own taste. It has many advantages since self selected reading enhance enthusiasm besides the skill as the main one. Interesting reading will provide interesting reading material apart from the curriculum, to analyze and evaluate can bring back their interest in actual reading. As suggested by Shika, reading strategies should include; recognizing the script of a language, deducing the meaning and use of unfamiliar lexical items, understanding explicitly stated information, understanding information when not explicitly stated, understanding 
| Volume: 1 | Number: 2 | October 2016 | ISSN: 2503 - 4405|

conceptual meaning, understanding the communicative value of sentences and utterances, understanding relations within the sentence, understanding relations between the parts of a text through lexical cohesion devices, understanding cohesion between parts of a text through grammatical cohesion devices (Shikha 2012). The finding about the amount of free reading was strongly related to gain in literacy and language development is highly consistent with previous study (Sullivan and Brown, 2014) entitled "Can Second Language Acquire Reach high Levels of proficiency Through self Reading? An Attempt to Confirm Nation's (2014) Results".

\section{Constructivism}

Constructivism is a reaction to didactic approaches such as behaviorism and programmed instruction, constructivism states that learning is an active, contextualized process of constructing knowledge rather than acquiring it. As Vygotsky and also Piaget explained that constructivism is an active and constructive learning paradigm. Learners are the constructor of the information. They construct their own knowledge or the object reality actively. Novel information they get from the activity is linked to their prior knowledge. The Knowledge is constructed based on personal experiences and hypotheses of the environment. Learners continuously test these hypotheses through social negotiation. Each person has a different interpretation and construction of knowledge process. The learner is not a blank slate (tabula rasa) but brings past experiences and cultural factors to a situation.

Previous studies explained by Cooper, Ertmer \& Newby (1993); there is a common misunderstanding regarding constructivism is that instructors should never tell students anything directly but, instead, should always allow them to construct knowledge for themselves. This is actually confusing a theory of pedagogy with a theory of knowing. Constructivism assumes that all knowledge is constructed from the learner's previous knowledge, regardless of how one is taught. Thus, even listening to a lecture involves active attempts to construct new knowledge 
One of the ways to master a language is using it actively in the daily life. However, a foreign language cannot be used daily since the environments do not recognize it. One cannot get stimuli from the environment. Automatically, response is an impossible thing to do. In fact, those things are significantly needed in language learning. Consequently, one can have a self practice instead of daily conversation in the environment. Learning took place when learner had the opportunity to practice making the correct response to a given stimulus based on his prior knowledge. Every action is viewed as "an interpretation of the current situation based on an entire history of previous interaction" (Clancey, 1986). Though someone learn a language as second language or use it in his daily life, it does not mean that he will learn the second language smoothly. If he gets incorrect comprehension, it can be a problem since he will be accustomed to the incorrect one and without any negative evident, it become fossilization. Not all learners reach the completion stage for every grammatical structure. Many will continue to show non-target language variability in at least some grammatical features. It is for this reason that we can talk of fossilization; many learners stop developing while still short of target-language competence (Ellis, 2003).

The three apps can be a helpful media to maintain that problem, are totally free. Everyone is able to download freely without any charge to buy them. One will not need any registration, serial number, or temporal limitation of use. One just needs to download by his/her smartphone and install them. Those three apps collaboration will change an ordinary e-book into audible e-book or audio-book. By these apps, receptive skill; reading and listening skill, can be trained continuously in fun way. One can read an e-book easily by his smartphone in spare time or just listen to the book while he is doing dishes, exercising, walking around, sitting down in the waiting room or even laying on bed. The two activities can be done simultaneously to have bigger advantages. When someone is experienced by audio and visual to one object," it will increase activation in many structures known to be involved in emotion processing (including for example amygdala, hippocampus, parahippocampus, insula, striatum, medial ventral frontal cortex, cerebellum, fusiform gyrus)" (Baumgartner et al, 2006). The second advantage, one will know how to pronounce a difficult word he read. The third one, he will understand the story faster. The fourth, one can find the meaning of a difficult 
| Volume: 1 | Number: 2 | October 2016 | ISSN: 2503 - 4405|

word to increase vocabulary as FB reader is completed by dictionary feature. Many advantages are provided by simple and free thing which possessed by many people recently. However the three applications must be collaborated to convert ordinary e-book into audible e-book.

\section{FBReader}

FBReader is one of free e-book reader application in the Google play which has more features than other e-book readers. It is a product of geometerplus. Based on explanation fbreader.org, some features of FBReader are:

1. Geometerplus makes its interface resemble to a physical book. Flip over effect will appear when one slides to the next page or push volume button. There is also a progress bar in the bottom of the screen. It lets you find out the page you look for faster, number of the page, and in what page you are.

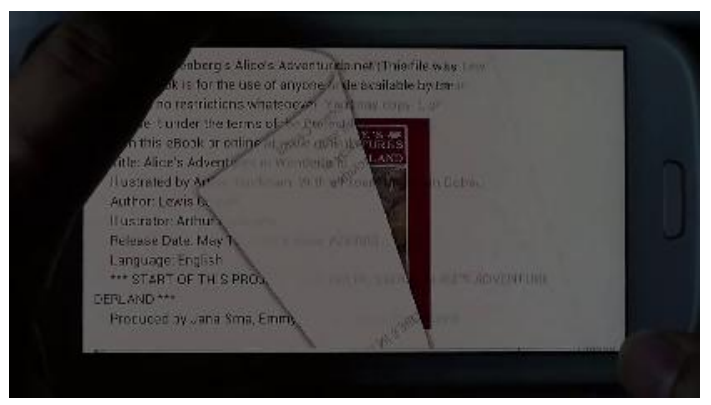

Picture 1: Flip over effect.

2. It can be used as gateway since it is integrated to some e-book provider. It means people are able to find and download other e-book across various bookstore and website on the internet

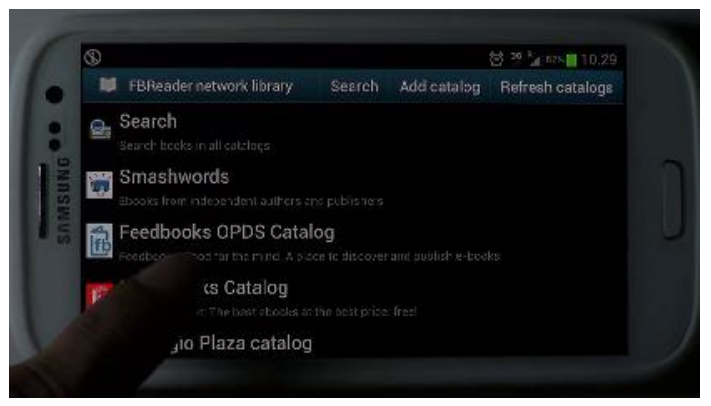

Picture 2: E-book provider integrated. 
3. It has library feature which organize the e-book on some categories to find the e-book in the phone memory easier. It browse based on author, tittle and tag or one can browse saved e-book in the local disk or SD card. One can also share his e-book to other by Bluetooth, dropbox or email.

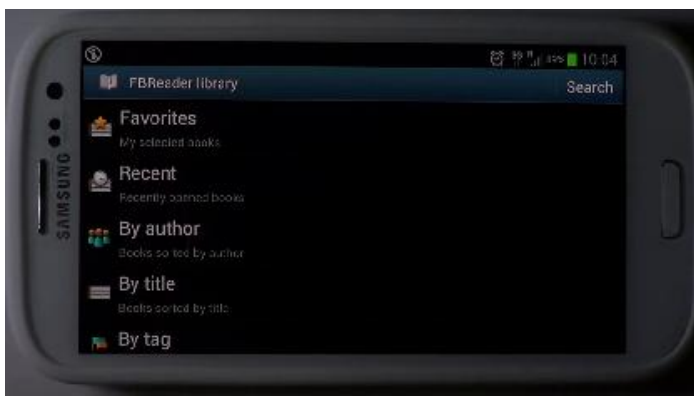

Picture 3: categories of library organization.

4. The next is customization features. Some feature can be customized based on user taste. One of them is night feature on the back of the book. Background color can be adjusted to make the readers comfortable while reading. Besides, appearance, text, color and wallpaper, margin etc are other features of pleasure enhance

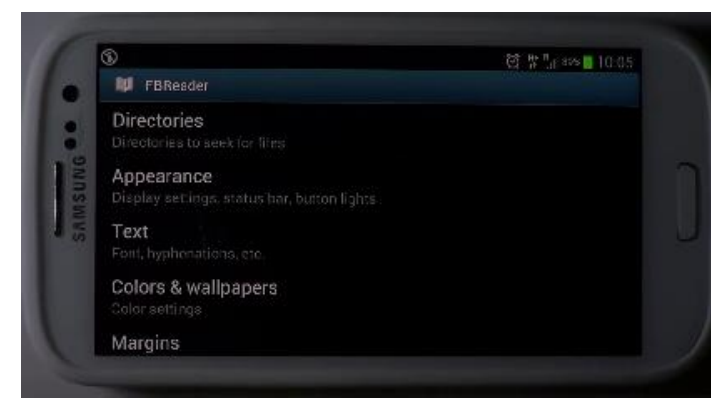

Picture 4: Some adjustment feature for readers.

5. One can select one word by clicking it to perform dictionary look up. It is integrated to some dictionary apps and website so one is not constrain with 1 specific dictionary.

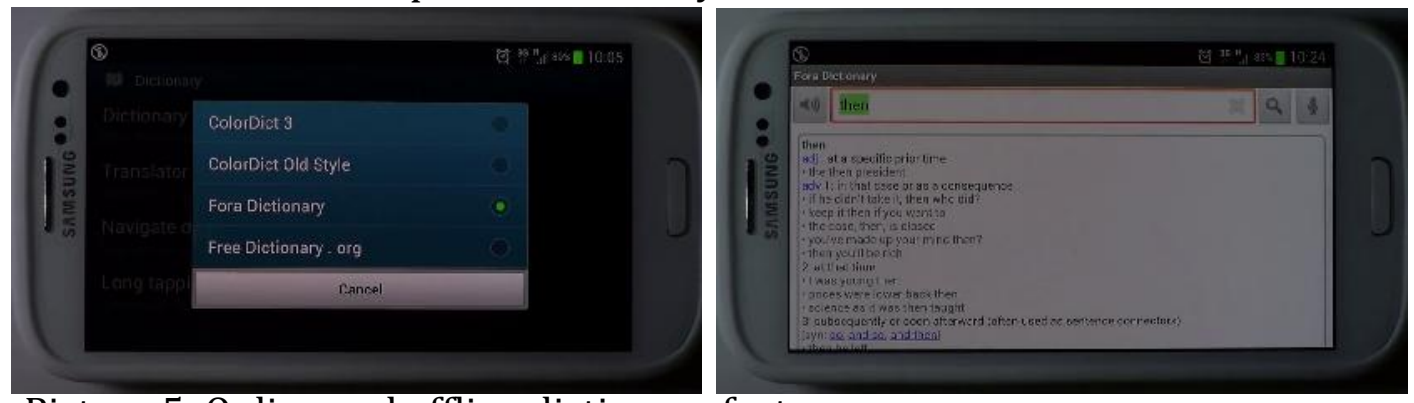

Picture 5: Online and offline dictionary feature. 
| Volume: 1 | Number: 2 | October 2016 | ISSN: 2503 - 4405|

As a reader application, it is compatible to some extensions of e-book and also platforms;

1. EPUB : all the main features except the tables. CSS support is not full.

2. EPUB3 : does not support most of ePub 3 specific features

3. Mobipocket : opens non-encrypted *.mobi files. DRM-protected files are not supported.

4. FB 2.0 : fully supported

5. FB 2.1 : lacks support of tables

6. HTML : limited, sufficient support

7. Plain text : supported, might not correctly split text into paragraphs.

8. RTF : subset of RTF

9. DOC (Microsoft Word) : subset of DOC

10. PDF :via separate plugin with third-party library

11. DjVu : via separate plugin

12. DAISY 3 : added to Go Read for Bookshare on Google Play

It supports some platforms; Android, Microsoft Windows, BlackBerry 10, Mac OS X, FreeBSD, Linux, mobile Linux devices ( Sharp Zaurus with Qtopia-based ROMs, pdaXrom or OpenZaurus ROM, Siemens Simpad with Opensimpad 0.9.0/Opie ROM, Nokia 770/N800/N810 Nokia Internet tablets, Pepper Pad 3, Motorola E680i/A780 smartphones, Digital Reader 1000 and Digital Reader DR800SG, Hanlin eReader etc). However, it needs other softwares to create audiobook in the smartphone. FB reader need plugin to make it audible.

\section{FBReader TTS Plugin}

FBReader is just a reader application. In order to make an e-book audible other applications are needed, they are FB reader TTS plugin and Ivona. TTS means text to speech, so this apps is functioned as converter of text in the e-book into a voice. Its site, fbreader.org, stated that it is a special enhancement for FBReader which is created by FBReader author. However, it has been developed by Hyperionics so that it has better performance;

1. Bluetooth play/pause and previous/next controls are handled correctly. 
2. Plays in the background and Bluetooth controls are still handled, for example to use playing music on your phone and listening to your book at the same time, and pausing/resuming playback as needed.

3. Android 4.2 and higher - lock screen widget to pause/resume, next/previous sentence, view book title and progress. This widget can be also used on the home screen under older versions of Android.

4. Read by sentences - the plugin pauses and resumes at individual sentences, instead of entire paragraphs. Upon resume, you don't have to listen from the beginning of a long paragraph again.

5. Enhanced control panel to set book language, open system TTS Settings to change speech engine, control speech rate, pitch and volume.

6. The control panel can be minimized to display only a row of small buttons at the bottom over the main FBReader screen, if you want to watch the text it reads at the same time.

7. Sleep timer.

8. Can highlight individual sentences instead of full paragraphs, but this requires a small code change in the main FBReader code.
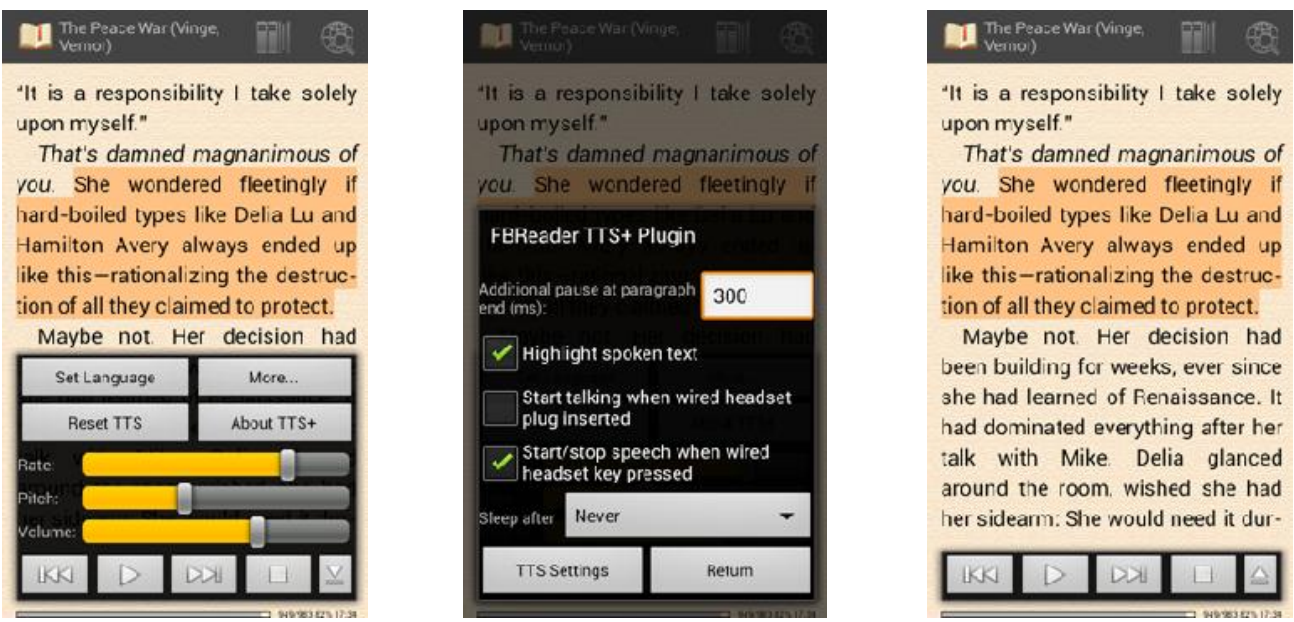

Picture 6: FBReader TTS plugin interface. 
| Volume: 1 | Number: 2 | October 2016 | ISSN: 2503 - 4405|

However, nothing is perfect. Some people said that this plugin product can't pronounce contractions, certain intonation etc. It can be solved by adding other software. It is Ivona text to speech.

\section{Ivona}

As described by Kaszczuk and Osowskion at Ivona text to speech system at Blizzard Challenge 2006, it consists of two parts inside; front-end and back-end. Front-end has two duties to do. The first is recognizing any text contains symbols such as abbreviation or number. It finds the same one for the written form which is called normalization. For the second duties, it conveys the phonetic transcription, give the text some marks and also divide the text into phrases, clauses and sentences ended up on the symbolic linguistic representation. After that back-end converts it into sound based on the recorded sound data base which is called synthesizer. The data base contains segmentations of all utterances. They are segmented by speech recognizer into phone, syllables, morphemes, words, phrases, and sentences. It results a natural, accurate sound and comprehensible.

So Far, Ivona supports for some language; English (Us), English (Uk), English (Au), English (Ind), English (Welsh), Welsh, Danish, Dutch, French, French Canadian, German, Icelandic, Italian, Polish, Portuguese, Brazilian, Romanian, Russian. Recently, Ivona are having bilateral agreement with Gajah Mada University to make it supports for Javanese language.

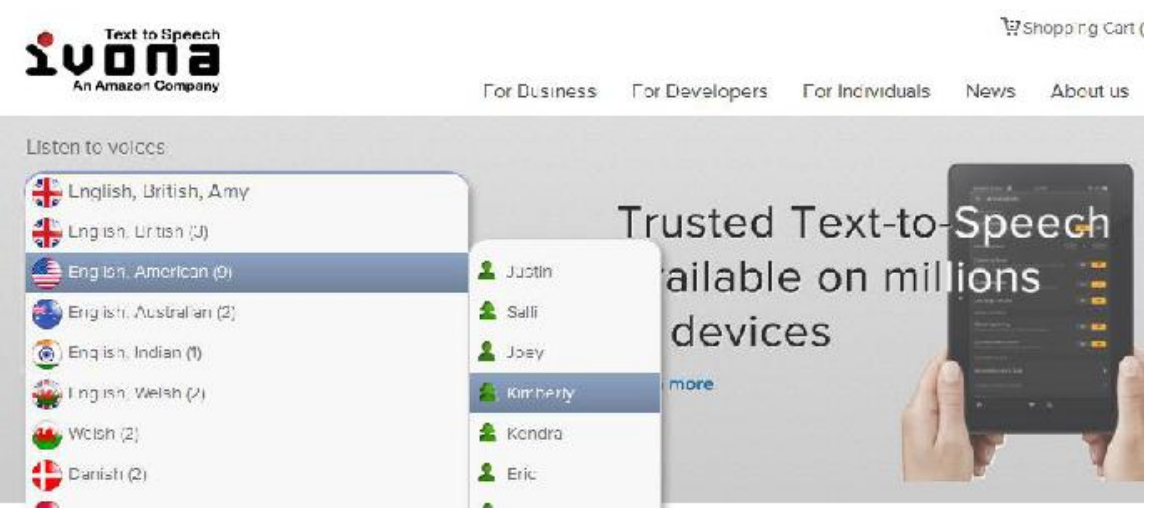

Picture 7: Ivona TTS index page. 


\section{Conclusion}

Audiobook is more interesting than e-book. The conversion of them will be usefull for learners to develop their competence. There are three applications needed to convert an e-book into audiobook. FBReader, FBreader TTS plugin and Ivona are free applications which can be downloaded easily. Some advantages of the collaboration are 1) reading and listening skill can be trained continuously in fun way. One can read an e-book easily by his smartphone in spare time or just listen to the book while he is doing dishes, exercising, walking around, sitting down in the waiting room or even laying on bed. 2) One will know how to pronounce a difficult word he read. 3) One will understand the story faster. 4) One can find the meaning of a difficult word to increase vocabulary as FB reader is completed by dictionary feature. 5) One can choose book based on his own taste. 6) It is completely free. One can also find e-book anytime, anywhere since it is integrated with e-book provider or just copy his own e-book into the smartphone. Those three applications collaboration is suitable media for receptive skill development. In other word, learners do not depend on teacher to get the material but he himself can be a provider.

\section{Reference}

Cooper, P. A. (1993). Paradigm Shifts in Designed Instruction: From Behaviorism to Cognitivism to Constructivism. Educational technology, 33(5), 12-19.

Clancey, W.J. (1986). Review of Winograd and Flores' understanding computers and cognition: A favorable interpretation. (STAN-CS-87-1173) Palo Alto, CA: Department of Computer Science, Stanford University.

Ellis, Rod. 2003. Second Language Acquisition. Hongkong: Oxford University Press.

Ertmer, P. A., \& Newby, T. J. (1993). Behaviorism, cognitivism, constructivism: Comparing critical features from an instructional design perspective.Performance improvement quarterly, 6(4), 50-72.

Lindsay, C. and Knight, P. (2006) Learning and Teaching English. Oxford: OUP.

Lukasz Osowski \& Michal Kaszczuk. (2006). Evaluating Ivona Speech Synthesis System for Blizzard Challenge 2006. IVO Blizzard 2006 Entry. Blizzard Challenge 2006 Workshop.

Piaget, J. (2013). The construction of reality in the child (Vol. 82). Routledge. 
| Volume: 1 | Number: 2 | October 2016 | ISSN: 2503 - 4405|

Seetha, Shikha.(2012). "Communication skills for engineers in global arena." International Journal on Arts, Management and Humanities (1.1) 1-6.

Sullivan, A. \& Brown, M. (2014). Vocabulary from Adolescence to Middle Age. London: Centre for Longitudinal Studies, Institute of Education, University of London.

Thirupathi, Vennum in "Technological Approach In English Language Teaching:New ,Vol1. Issue\%204/THIRUPATHI\%20VENNUM\%2055-60.pdf Accessed on 9th March 2015 Y.Sreenivasulu and Dr .R.V. Jayanth Kasyap in "Need of Teaching Oral Communication Skills in Technical Institutes of A.P: A Critical Outlook" ijellh.com/papers/2014/july/08-68-74-july- 2014.pdf Accessed on 25th March, 2015

Thomas Baumgartner, Kai Lutz, Conny F. Schmidt, Lutz Jäncke, The emotional power of music: How music enhances the feeling of affective pictures, Brain Research, Volume 1075, Issue 1, 23 February 2006, Pages 151-164, ISSN 00068993, http://dx.doi.org/10.1016/j.brainres.2005.12.065.

Vygotsky, L. S. (1980). Mind in society: The development of higher psychological processes. Harvard university press.

Website:

Ivona

www.ivona.com

FBReader

fbreader.org

TTS Bahasa Jawa

https://id.techinasia.com/google-ugm-buat-text-to-speech-bahasa-jawa 